\title{
Douvaine - Les Balaries
}

\section{Franck Gabayet}

\section{OpenEdition}

Journals

Édition électronique

URL : http://journals.openedition.org/adlfi/14910

ISSN : 2114-0502

Éditeur

Ministère de la culture

\section{Référence électronique}

Franck Gabayet, «Douvaine - Les Balaries », ADLFI. Archéologie de la France - Informations [En ligne], Rhône-Alpes, mis en ligne le 28 mai 2015, consulté le 19 avril 2019. URL : http://

journals.openedition.org/adlfi/14910

Ce document a été généré automatiquement le 19 avril 2019

(c) Ministère de la Culture et de la Communication, CNRS 


\title{
Douvaine - Les Balaries
}

\author{
Franck Gabayet
}

Lien Atlas (MCC) :

http://atlas.patrimoines.culture.fr/atlas/trunk/index.php?

ap_theme=DOM_2.01.02\&ap_bbox=6.273;46.289;6.328;46.326

1 En dépit de nombreuses mentions de vestiges sur le territoire de la commune de Douvaine, tombes de l'âge du Bronze et de l'âge du Fer, découvertes de mobilier antique, dédicace à une divinité auguste ou encore coffrages de dalles alto-médiévaux, les récents sondages de diagnostics n'avaient pu mettre en évidence de traces d'occupation ancienne. C'est chose faite avec l'opération des Balaries, qui a été l'occasion de repérer au printemps 2013 une construction, certes partielle, que le mobilier associé invite à placer dans un Bas-Empire aux contours flous. Les résultats forcément limités du diagnostic permettent de restituer, avec des réserves qui ne sont plus à rappeler du fait même de l'exercice, un bâtiment construit sur de solides solins de pierre et probablement doté d'élévations de terre. Un sondage a permis de dégager l'angle sud-est d'une pièce, qui, par déduction un peu osée, il faut bien l'avouer, pourrait se développer sur près de $13 \mathrm{~m} \mathrm{du}$ nord au sud pour $12 \mathrm{~m}$ d'est en ouest, soit une superficie intérieure de l'ordre de $156 \mathrm{~m}^{2}$. Le bâtiment dispose de sols de terre battue amendée de graviers et de petits galets dont la densité varie en fonction de la topographie.

2 Les marqueurs chronologiques sont des plus minces. Le mobilier extrait des différentes unités stratigraphiques est exclusivement constitué de fragments de tuiles (tegulae) et de tessons de céramiques antiques, dont la chronologie ne peut guère être précisée. En revanche, la fouille de quelques décimètres carrés de sol a livré deux tessons de pierre ollaire dont la production est courante au Bas-Empire, tout en débordant sur la période alto-médiévale. En l'absence d'autres jalons chronologiques, c'est sans doute autour de cette période qu'il convient de situer, au moins à titre d'hypothèse, l'occupation de l'édifice.

3 Si aucune structure archéologique n'a été identifiée, à l'exception d'un trou de poteau dans le sondage 3, environ $100 \mathrm{~m}$ au nord-ouest du bâtiment, une unité stratigraphique 
est repérée sur quasiment l'intégralité de l'emprise. Elle permet de restituer un vague horizon, d'une épaisseur de l'ordre de 0,30 m, qui livre quelques résidus de terres cuites architecturales, probablement des fragments de tuiles ou de briques antiques, mais aussi des tessons usés de céramique gallo-romaine.

INDEX

Index chronologique : Bas-Empire, Moyen Âge

Mots-clés : bâti, céramique, tegula

operation Opération préventive de diagnostic (OPD), 2013 - n OA : 2211232

Index géographique : Rhône-Alpes, Savoie (73), Douvaine

\section{AUTEURS}

FRANCK GABAYET

Inrap 